\title{
Utility before business
}

\author{
Steven M. Teutsch, MD, MPH${ }^{1}$, Jonathan E. Fielding, MD, $\mathrm{MPH}^{1-3}$, Muin J. Khoury, MD, $\mathrm{PhD}^{4,5}$ and \\ James P. Evans, MD, PhD ${ }^{6}$
}

Today, enthusiasm for genomics far outstrips the relatively modest, albeit increasing, number of clinical scenarios for which it provides established health benefits. ${ }^{1}$ Nonetheless, laboratories have incentives to introduce and offer genetic tests at an astounding rate, reflecting not only the increased ability to perform them accurately in many clinical laboratories but the precipitous drop in the cost of testing. However, the actual cost of the tests themselves should be the least of our concerns; the clinical usefulness should be foremost. This set of circumstances has many similarities to that of newborn screening, for which the costs of the tests themselves have plummeted and the marginal cost of additional tests is so low as to be insignificant, supporting the argument that we should do every possible test. However, the overriding question for both genetic testing and new tests that could be added to newborn screening is the same: What are the health benefits achieved and harms incurred as a result of the information gained from these tests?

The Secretary's Advisory Committee on Genetics, Health, and Society ${ }^{2}$ and the Evaluation of Genomic Tests in Prevention and Practice Working Group ${ }^{3}$ wrestled with the question of the clinical utility of genomic testing, including its definition and its relationship to oversight of laboratory testing. The Secretary's Advisory Committee on Genetics, Health, and Society clearly came down on the side of stricter oversight of genomic testing, emphasizing that, in general, clinical use of tests should be deferred until clear evidence of clinical utility is demonstrated, as it has been in guiding some cancer chemotherapies, for example.

The Committee's recommendation may seem harsh. After all, what harm is there in a laboratory test? The genetic test itself has negligible harms, but its consequences can be substantial, including a cascade of tests, procedures, and treatments that, for an unproven test, are of uncertain benefit, and many of which are associated with harms, both physical and psychological. ${ }^{4}$ In addition, the unnecessary costs of these tests and ensuing services contribute to the more than $\$ 750$ billion wasted by the health-care system each year. ${ }^{5}$ The money spent on tests with unproven health benefit could be better spent on ensuring delivery of beneficial services, to say nothing of being directed toward underlying behavioral, social, and environmental determinants of health that contribute to healthier individuals and communities and a more economically competitive nation. ${ }^{6}$

It is against that backdrop that we should consider the article by Crawford et al. ${ }^{7}$ in this issue of Genetics in Medicine. This College of American Pathologists-sponsored survey sought information about the business case for implementation of early institutional adopters (all of which were academic medical centers) of next-generation sequencing (NGS). The centers surveyed offered whole-exome and whole-genome sequencing. Whatever the rationale for the study, the survey neglected to first assess central and difficult issues-these leaders' perceptions of the clinical utility of NGS and their reasons for being early adopters. These institutions surely faced challenges in establishing procedures and ensuring financial viability, among other concerns. But what were the motivations to introduce NGS in the first place? Was it to be perceived as scientific leaders? If so, then NGS should have been introduced as a research tool rather than a clinical tool. Was it to be perceived as a market leader, at the cutting edge of current technologies-a perception that could enhance marketing programs? If so, then the primary reason for adoption of this technology is responding to economic incentives, to enhance prestige and facilitate promotion of "cutting edge" services by medical centers without sufficient concern about utility or costs to patients or health plans. Was it merely because NGS is now considered "affordable" and competitive with specific genetic tests of demonstrated value? If so, then it is important to consider the downstream medical and financial consequences of testing. Where were the ground rules for what to do with all the results of testing? A well-understood ethical conundrum is what to do with the all the data from NGS. On the one hand, withholding results from patients and physicians deprives them of the ability to act on them, whereas on the other, the overwhelming amount of information is extraordinarily difficult to interpret and communicate. Patients are notoriously poor at understanding risk, so they may misconstrue the meaning of the incidental findings, leading to inappropriate use of the information or creating needless psychological distress. Guidance on how to present the data in a useful fashion and

${ }^{1}$ Department of Public Health, Los Angeles County, Los Angeles, California, USA; ${ }^{2}$ Fielding School of Public Health, University of California, Los Angeles, California, USA; ${ }^{3}$ Schools of Medicine, University of California, Los Angeles, California, USA; ${ }^{4}$ Office of Public Health Genomics, Centers for Disease Control and Prevention, Atlanta, Georgia, USA;

${ }^{5}$ Epidemiology and Genomics Research Program, National Cancer Institute, Bethesda, Maryland, USA; ${ }^{6}$ School of Medicine, University of North Carolina, Chapel Hill, Chapel Hill,

North Carolina, USA. Correspondence: Steven M. Teutsch (steventeutsch@gmail.com; teutsch@comcast.net) or Jonathan E. Fielding (jfielding@ph.lacounty.gov) 
to fully incorporate informed patient preferences is critically needed. All this should shape what gets reported to physicians and what to patients and how. Does the introduction of NGS need to await the availability of clinical decision-support systems that can ensure the data are tailored to the patient's current and future clinical situation? The leaders interviewed clearly recognized that few physicians in their organizations were prepared to use the new trove of data wisely-and how could they, given the complexity and uncertainty?

The current indications for NGS with proven utility are still relatively limited but potentially great in the future. Major advances have recently occurred in the use of whole-exome/ whole-genome sequencing in the diagnosis and management of patients and families with suspected rare Mendelian disorders, to the point that Blue Cross Blue Shield Association Technology Evaluation Center gave it a "favorable" review in 2013. ${ }^{8}$ But even there, many logistical, scientific, and practical issues arise that do not currently permit routine use of this technology outside of research protocols. ${ }^{9}$ Moreover, the avalanche of "incidental findings" from genome sequencing will have to be carefully dealt with, as reflected in recent American College of Medical Genetics and Genomics recommendations on return of results. ${ }^{10}$ Finally, the notion of "next-generation sequencing" itself is highly heterogeneous and can refer to anything from the targeted sequencing of a carefully selected panel of genes in a malignant tumor to whole-exome or whole-genome sequencing of the germ line. Clinical medicine has taught us that optimal testing usually consists of asking clinically relevant, focused questions and avoiding overly broad "shotgun" testing that begs for misinterpretation and a plethora of incidental findings. It would be surprising if DNA sequencing were any different. Thus, genetics must grapple with the questions of not only when to apply massively parallel sequencing but also what to sequence. That is, when should sequencing be confined to sets of genes and when should the whole genome (or exome) be the target? Only through carefully considered research (such as that currently sponsored by the National Human Genome Research Institute) will we begin to understand how best to apply these powerful new technologies to clinical medicine.

It is entirely understandable that laboratories need to gain experience in using this powerful new technology to ensure the accuracy of testing and develop the appropriate quality-control systems. But that experience should be gained along with careful standard setting, oversight, and evaluation before widespread introduction. As the Analytic Validity, Clinical Validity, Clinical Utility and Associated Ethical, Legal and Social Implications Model Project, ${ }^{11}$ the Evaluation of Genomic Tests in Prevention and Practice Working Group, the Secretary's
Advisory Committee on Genetics, Health, and Society, and others ${ }^{12}$ have pointed out, analytic validity and clinical validity are necessary but not sufficient conditions for use. Without demonstrated utility, the potential for waste and harms outweighs hypothetical benefits. Professional, laboratory, and clinical organizations have the responsibility to ensure appropriate use. The widespread clinical introduction of NGS before we know how best to use the data is unwise, unhealthy, and costly. Although NGS has the potential to add value to personal health care in the future, use today will more likely produce unnecessary care, related costs, and psychological harms.

Evaluations such as the one in this issue of Genetics in Medicine $^{7}$ have great potential to inform the thoughtful introduction of whole-genome sequencing and other diagnostic tools, but they need to ask and answer the right questions, the important questions, not just the practical and business ones.

\section{DISCLOSURE}

The authors declare no conflict of interest.

\section{REFERENCES}

1. Dotson WD, Douglas MP, Kolor K, et al. Prioritizing genomic applications for action by level of evidence: a horizon-scanning method. Clin Pharmacol Ther 2014;95:394-402.

2. US System of Oversight of Genetic Testing. A Response to the Charge of the Secretary of Health and Human Services. US Department of Health and Human Services, 2008. http://www4.od.nih.gov/oba/sacghs/reports/sacghs_oversight_ report.pdf. Accessed 11 May 2014

3. Botkin JR, Teutsch SM, Kaye Cl, et al.; EGAPP Working Group. Outcomes of interest in evidence-based evaluations of genetic tests. Genet Med 2010;12:228-235.

4. Evans JP, Khoury MJ. The arrival of genomic medicine to the clinic is only the beginning of the journey. Genet Med 2013;15:268-269.

5. Institute of Medicine. Best Care at Lower Cost: The Path to Continuously Learning Health Care in America. National Academies Press: Washington, DC, 2013

6. McCullough JM, Zimmerman FJ, Fielding JE, Teutsch SM. A health dividend for America: the opportunity cost of excess healthcare expenditures in the United States. Am J Prev Med 2012;43:650-654.

7. Crawford JM, Bry L, Pfeiffer J, et al. The business of genomic testing: a survey of early adopters. Genet Med 2014;16:954-961 (this issue).

8. Blue Cross Blue Shield Association. Special report: exome sequencing for clinical diagnosis of patients with suspected genetic disorders. 2013. http://www.bcbs. com/blueresources/tec/vols/28/28_03.pdf. Accessed 11 May 2014.

9. Feero WG. Clinical application of whole-genome sequencing: proceed with care. JAMA 2014;311:1017-1019.

10. Berg JS, Grody WW, Kalia SS, et al; American College of Medical Genetics and Genomics. ACMG recommendations for reporting of incidental findings in clinical exome and genome sequencing. Genet Med 2013;15:565-574.

11. Haddow JE, Palomaki GE. ACCE: A model process for evaluating data on emerging genetic tests. In: Khoury M, Little J, Burke W (eds). Human Genome Epidemiology: A Scientific Foundation for Using Genetic Information to Improve Health and Prevent Disease. Oxford University Press: New York, 2003:217-233.

12. Grosse SD. Economic analyses of genetic tests in personalized medicine: clinical utility first, then cost utility. Genet Med 2014;16:225-227. 